\begin{tabular}{|l|l|}
\hline \multicolumn{2}{|l|}{ EDUCAC̄̃O } \\
\hline ROS & ROSELI MORENA PORTO \\
\hline
\end{tabular}

\title{
RASGUEM \\ O PLANO \\ DE NEGÓCIO
}

0 desenvolvimento do espírito empreendedor,

o entendimento da diversidade e a experiência

intercultural adicionam muito valor ao aprendizado de um empresário que deseja obter sucesso profissional

INTERNACIONALIZAÇÃO E DIVERSIDADE. A principal habilidade de um bom gestor nos dias de hoje é manter-se atento ao que acontece no mundo, mas sem perder a visão local. Independentemente de ser global ou local, o enfrentamento dos desafios organizacionais passa pelo entendimento da diversidade e pelo desenvolvimento do espírito empreendedor. Nesse contexto, o processo de internacionalização nas áreas de graduação e formação executiva tem auxiliado e impulsionado essas demandas, principalmente, pela grande mobilidade de alunos e de professores nas duas direções. A cada semestre, a FGV-EAESP recebe mais de 100 alunos estrangeiros oriundos das escolas de negócios parceiras, e para elas envia seus alunos para realizarem os programas de intercâmbio, entre os quais se destacam os já consagrados Summer Programs, que oferecem cursos no mês de julho, quando as escolas do Hemisfério Norte estão no período de férias de verão.
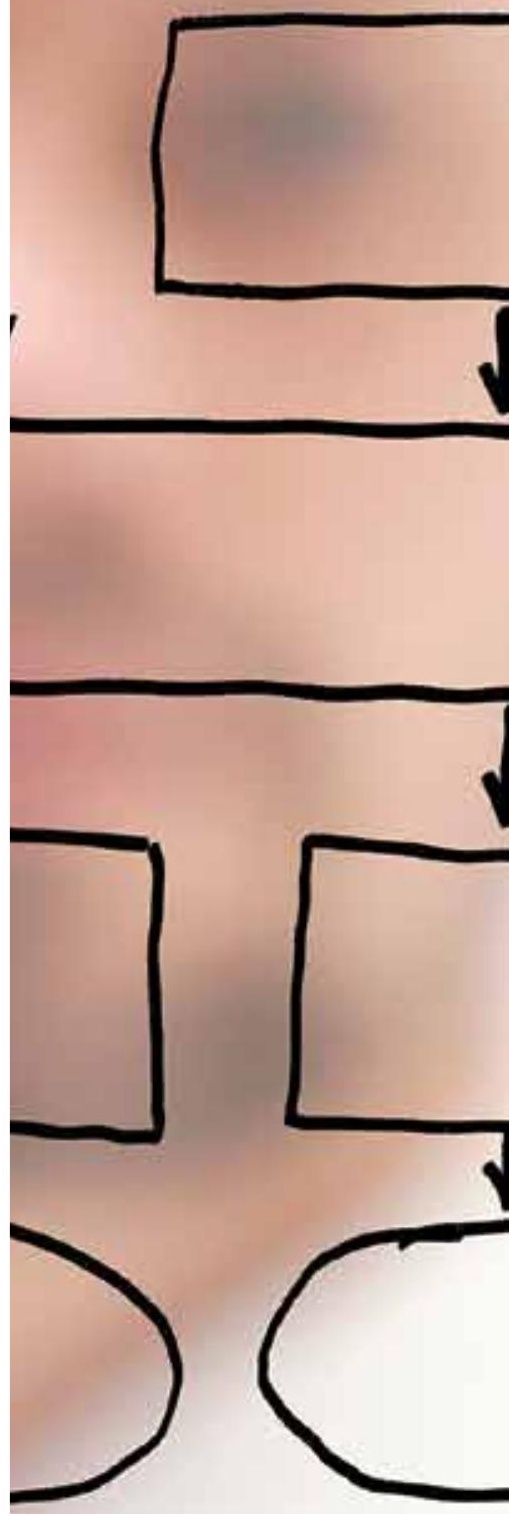
Um desses cursos é realizado no Babson College, referência mundial na área de Empreendedorismo. Fundada em 1909 por Roger Ward Babson, seu lindo campus arborizado está localizado em Wellesley, nos arredores de Boston, no estado americano de Massachusetts. Trata-se do Entrepreneurship Program, inicialmente desenvolvido para os alunos do Curso de Especialização em Administração de Empresas para Graduados (CEAG). Em 2009, apenas dois anos depois de estabelecido o convênio entre as duas instituições, o programa foi adaptado para ser oferecido também para os alunos da graduação. O curso tem duração de duas semanas, sendo 30 horas-aula semanais. As aulas são ministradas em período integral, com ritmo intenso e baseadas no método do caso. Nos próximos parágrafos, descrevo minha experiência como coordenadora do Entrepreneurship Program Babson College - FGV-EAESP em 2011, que contou com a participação de 27 alunos de pós-graduação e 27 alunos de graduação, respectivamente, na primeira e na segunda quinzena de julho.

\section{A principal habilidade de um bom gestor é manter-se atento ao que acontece no mundo, mas sem perder a visão local}

O grupo de pós-graduação foi composto por alunos e ex-alunos do CEAG e GVpec, com funções executivas em empresas como Itaú-Unibanco, IBM, Brasken, Grupo Iguatemi, Procter \& Gamble, Pöyry, e com formação em diversas áreas como Direito, Arquitetura, Engenharia, Veterinária e Administração. Já o grupo de graduação foi formado principalmente por alunos do curso de Administração de Empresas, com idade entre 18 e 20 anos.

ALUNOS E EXECUTIVOS. O que leva executivos bem-sucedidos e já estabelecidos em grandes empresas ao interesse pelo tema Empreendedorismo? Segundo os relatos dos alunos, eles têm dois objetivos. No curto prazo, aproveitar os ensinamentos em seu dia a dia dentro das organizações que incentivam, cada vez mais, o intraempreendedorismo. Mas o principal foco é o longo prazo, o plano alternativo para ser executado quando já não tiverem mais espaço nas empresas, seja pela idade, seja pelo desencanto com a vida executiva. Assim, já se preparam para enfrentar o desafio e desejo de ter o próprio negócio. Para um dos participantes do programa, a experiência em Babson serviu para antecipar sua determinação em abrir sua própria empresa: "Este aprendizado tem me ajudado nesse novo empreendimento, principalmente a ideia de que pequenos negócios são muito mais influenciados por pequenos eventos aleatórios do que por mudanças na macroeconomia do país, por exemplo."

Uma questão operacional importante enfrentada pelos alunos foi a ausência no trabalho. Enquanto alguns preferiram utilizar o período de férias para acompanhar as aulas e, assim, evitar ter que conciliar a vida executiva com a vida de aluno, outros tiveram apoio da própria empresa para participar do programa. Como a área do campus oferece 
facilidades como o acesso à internet, os alunos conseguiam manter seus e-mails em dia e responder a distância às demandas de suas respectivas organizações.

No Babson College, o conteúdo das tradicionais disciplinas do campo da Administração segue a abordagem Effectuation para o ensino do Empreendedorismo. Diferentemente da lógica causal direcionada para a elaboração do plano de negócio, na Effectuation o empreendedor experimenta distintas estratégias e combinações de recursos que já estejam em seu controle. Dessa forma, todo o esforço inicial do empreendedor deve ser na interação com o cliente, seguida pela venda do conceito e, por fim, pela consolidação da ideia em um produto ou serviço que tem por objetivo resolver o problema identificado.

“RASGUEM O PLANO DE NEGÓCIO". Já no primeiro dia de aula, o professor Bob Caspe, que leciona Marketing para Empreendedores, desafiou os executivos a entrevistarem amigos para identificarem algum problema enfrentado por eles, em suas empresas no Brasil, que pudesse ser resolvido com tecnologia (uma nova forma de executar uma tarefa, um novo olhar sobre uma situação, uma racionalização de um processo). Esse exercício revela outra característica do ensino no Babson College: o foco no B2B. Com sua experiência de inúmeros empreendimentos bem-sucedidos, Bob foi categórico ao afirmar para espanto de todos - que nunca escreveu um único plano de negócios. Outra afirmação que causou polêmica foi: "Venture capital is dangerous - se optar por ele, o empreendedor nunca será dono de seu próprio negócio, apenas o funcionário de um fundo de capital."

Segundo o professor Jay Rao, as oportunidades de novos negócios estão escondidas em problemas operacio-

\section{A maior chance de sucesso acontece para empreendedores que já trabalharam em empresas grandes e aprenderam o que dá certo e o que dá errado}

nais nas empresas já estabelecidas. Em sua aula de Inovação para os alunos de graduação, o professor Rao afirmou que o objetivo do empreendedor deve ser o desenvolvimento da parceria, resolvendo um problema operacional para melhorar a prestação de serviço para o consumidor final dessa empresa. Para que o empreendedor entenda a proposição de valor, é preciso aproximar-se do cotidiano da empresa, estudar em detalhe seus processos internos para encontrar a solução do problema identificado. Depois, é só replicar o modelo para outras empresas com o mesmo problema. Estatísticas comprovam que a maior chance de sucesso acontece para empreendedores que já trabalharam em empresas grandes e aprenderam o que dá certo e o que dá errado. Com olhar incisivo, o professor Rao ressalta: "Cada erro que uma grande empresa comete é uma oportunidade para uma pequena empresa."

Segundo a abordagem do Babson College, se o foco inicial do empreendedor é a interação com o cliente, o produto inicial não precisa ser perfeito: uma versão simples que traga alguma redução de custo ou aumento da produtividade é mais fácil para convencer a empresa parceira. Essa versão simples possibilita incrementos futuros, 
decorrentes da melhor compreensão do problema e consolidação da parceria. Novas versões possibilitam novas formas de ganho. O caso do Skype é citado para ilustrar essa situação. No início, seu serviço era precário, mas solucionava o problema de comunicação sem custo, pois eliminava a digitação de conversas via computador, tornando o contato mais rápido com a rede de relacionamento. A Apple também cresceu vendendo computadores pessoais para os early adopters, que não sabiam o que era high performance. Seus primeiros produtos foram direcionados para vendedores e profissionais liberais sem recursos nem experiência prévia para comparar performance, diferentemente dos funcionários de grandes empresas, que eram usuários dos potentes equipamentos IBM. Esses são exemplos de empresas que começaram pequenas, fazendo produtos com baixa qualidade e que grandes empresas não conseguiam criar.

VENDER, VENDER E VENDER. Para a execução dessa abordagem com foco na identificação de problemas e desenvolvimento de parcerias, os alunos foram expostos a alguns exercícios para aprimoramento das habilidades de comunicação. Na aula Value \& Category, o poder de síntese foi exercitado pelos alunos-executivos no Elevator Pitch. A dinâmica consiste em vender, em, no máximo, 30 segundos, a melhor proposição de valor, de acordo com o perfil de um cliente potencial, durante uma viagem de elevador: um investidor, um potencial empregador ou uma consumidora exigente. Para os alunos de graduação, coube o Rocket Pitch: uma apresentação de três minutos utilizando, no máximo, três slides. No último dia do curso, jovens sem nenhuma experiência profissional portaram-se como verdadeiros empreendedores, persuadindo a plateia para a oportunidade identificada, produto ou serviço que traria a solução do problema para o cliente, o modelo de negócio (diferencial competitivo, como obter lucro com ele) e, o

\section{Além da absorção de conteúdos em aulas, exercícios práticos e análise dos casos, a experiência intercultural potencializa o aprendizado}

mais importante, o call to action, ou seja, qual era a necessidade do grupo: conselho, investimento, recursos, etc.

Após 30 dias no campus do Babson College, percebi que o maior ganho para os participantes vai além da absorção do conteúdo nas aulas, exercícios práticos e análise dos casos. Há uma experiência intercultural que adiciona valor ao aprendizado. Como destaca um dos participantes: "O pragmatismo na tomada de decisão dos americanos contribuiu muito para que eu fizesse uma revisão total nas formas de atuação no meu dia a dia."

Durante o programa, eles tiveram a possibilidade de experimentar formas diferentes de didática, consolidar uma importante rede de relacionamento, conviver com alunos de países tão diferentes quanto Guatemala e Malásia, sentir como é viver em campus. Uma verdadeira descoberta do lado acadêmico do american way of life.

ROSELI MORENA PORTO, professora da FGV-EAESP,

roseli.porto@fgv.br 